\title{
An integrative review on the information and communication needs of parents of children with cancer regarding the use of complementary and alternative medicine
}

Trine Stub ${ }^{1 *}$, Agnete E. Kristoffersen ${ }^{1}$, Grete Overvåg ${ }^{2}$ and Miek C. Jong ${ }^{1}$

\begin{abstract}
Background: Parents often choose Complementary and Alternative Medicine (CAM) as a supportive agent with the aim to reduce cancer treatment-related symptoms in their children. Therefore, it is necessary to understand parents information and communication needs regarding CAM. The aim of the present study was to review the research literature as to identify the information and communication needs of parents of children with cancer, and the children themselves, regarding the use of CAM.

Methods: An integrative systematic review design was chosen. Searches were performed in AMED, CAMbase, CINAHL (Ebsco), EMBASE, PubMed and Psyclnfo, Theme eJournals and Karger. The search was limited to studies published in English, German, Dutch, and the Scandinavian languages. Using predefined inclusion and exclusion criteria, two reviewers independently screened the title and abstracts of the relevant papers. A data extraction form and critical appraisal checklists were used to extract data for analysis, and a mixed methods synthesis was applied.

Results: Out of 24 studies included, $67 \%$ were of quantitative and 33\% of qualitative study design. Five main themes emerged from the analysis of 21 studies: Information on CAM, sources of CAM information, communication about CAM, informed decision-making on CAM, and Risk/benefit of CAM. The majority of the parents did not disclose the CAM use of their children because they feared negative reactions from the attending oncologist. To make informed treatment decisions for their children, parents wanted unbiased information about CAM and would act accordingly. They demand open communication about these modalities and respect for the family's autonomy when choosing CAM for their children.

Conclusion: There is an urgent need for parents of children with cancer for high quality information on CAM from reliable and scientific sources. Development of authoritative evidence-based decision tools is thus warranted to enable health care professionals and parents of children with cancer to make well informed, individual decisions concerning CAM.
\end{abstract}

Keywords: Complementary health approaches, Complementary medicine, Paediatric oncology, Systematic review, Decision-making, Traditional medicine

\footnotetext{
* Correspondence: trine.stub@uit.no

${ }^{1}$ National Research Center in Complementary and Alternative Medicine (NAFKAM), Department of Community Medicine, Faculty of Health Sciences, UiT The Arctic University of Norway, Hansine Hansens veg 19, 9019 Troms $\varnothing$, Norway

Full list of author information is available at the end of the article
}

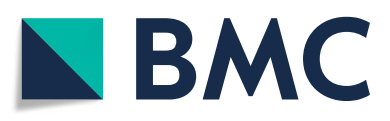

(c) The Author(s). 2020 Open Access This article is licensed under a Creative Commons Attribution 4.0 International License, which permits use, sharing, adaptation, distribution and reproduction in any medium or format, as long as you give appropriate credit to the original author(s) and the source, provide a link to the Creative Commons licence, and indicate if changes were made. The images or other third party material in this article are included in the article's Creative Commons licence, unless indicated otherwise in a credit line to the material. If material is not included in the article's Creative Commons licence and your intended use is not permitted by statutory regulation or exceeds the permitted use, you will need to obtain permission directly from the copyright holder. To view a copy of this licence, visit http://creativecommons.org/licenses/by/4.0/ The Creative Commons Public Domain Dedication waiver (http://creativecommons.org/publicdomain/zero/1.0/) applies to the data made available in this article, unless otherwise stated in a credit line to the data. 


\section{Background}

The symptom burden in children with cancer is high, and is reported to increase with disease progression and cancer-related treatment $[1,2]$. According to parents, symptoms such as pain, emotional distress, fatigue and loss of appetite cause the most problems for children undergoing cancer treatment [3]. Parents often choose Complementary and Alternative Medicine (CAM) as supportive agent with the aim to reduce these cancer treatment-related symptoms in their children [4]. CAM is defined as a group of diverse medical and health care systems, practices, and products that are not generally considered part of conventional medicine [5]. More specifically, if a non-mainstream practice is used together with conventional medicine, it is considered "complementary", and if a non-mainstream practice is used in place of conventional medicine, it is considered "alternative" [5]. Reported prevalence rates of CAM use among children with cancer vary between 6 and 100\% [6], depending on the definition of CAM, the sample, and country surveyed [7]. The prevalence of CAM use is on average $47.2 \%$ in high-income countries [7]. Additionally to using CAM as supportive care, parents also use CAM for treatment and cure of cancer in their children [7]. Abandonment of conventional cancer treatment in favor of CAM has been reported, and may have serious survival implications for children. A recent study in Thailand reported that the median survival duration in children who were diagnosed with acute leukemia and solely used CAM to cure cancer was 1 month, and their five-year survival rate $0 \%$ [8]. CAM modalities most commonly used in children with cancer are herbs, dietary and nutritional supplements, and spiritual treatments including faith, prayer, and healing $[6,7]$. Whereas patterns of CAM use have found to be different between treatment and post-treatment in adults with cancer [9], this does not seem to appear in children with cancer. A study by Turhan et al. [10] demonstrated that there was no difference in the use of herbs or vitamins/minerals/ nutrient supplements in children during chemotherapy treatment or after chemotherapy treatment.

Despite the high prevalence of CAM use in children with cancer, the majority of parents do not disclose CAM use to the attending oncologist or physician of the child [7]. Common reasons of parents not to tell about CAM are their belief that CAM is safe, fear of the physician's reaction, that the medical staff lacks knowledge, and that the physician does not ask [7]. However, parent-physician communication on CAM use in children with cancer is of utmost importance, not alone as to prevent the risk of decreased efficacy of conventional cancer therapy because of the potential interaction with CAM modalities such as herbs and dietary supplements $[11,12]$. Physicians acknowledge that it is important to know which CAM modalities their patients use, but they have little knowledge about them, and find themselves unable to inform parents about the safety and efficacy of CAM therapies $[13,14]$.

Other authoritative resources that parents may turn to for information are websites that advise patients on CAM use for cancer, such as the website of the National Cancer Institute [15], CAM cancer of NAFKAM (http:// cam-cancer.org), and the website of the National Center for Complementary and Integrative Health (https:// nccih.nih.gov). These websites however, are more directed towards cancer in adults and contain sparse to no information on the suitability of CAM modalities for use in children. Other sources that parents rely on to obtain information about CAM use are the Internet. Information from Internet is less reliable $[16,17]$ and can be overwhelming for parents. In addition, parents often learned about CAM from friends and family [18].

To develop future authoritative and reliable CAM resources, specifically for parents of children with cancer, it is necessary to understand which information and communications needs they have regarding CAM. Therefore, the present study was initiated with the aim to review the research literature as to identify the information and communication needs of parents of children with cancer, and the children themselves, regarding the use of CAM. To the best of our knowledge, no previous systematic review or protocol for such a planned review on information and communication needs of CAM of parents of children with cancer has been published.

\section{Methods}

\section{Design and objective}

There are several systematic approaches to review and synthesize the literature [19]. Given the aim of the study, an integrative review was deemed the most suitable type of review method. An integrative review is a specific review method that summarizes past empirical or theoretical literature to provide a more comprehensive understanding of a particular phenomenon or healthcare problem [20]. An integrative review allows for the inclusion of studies with different methodologies to more fully understand a particular phenomenon of concern [21]. The aim of this integrative review differs from the aim of a scoping review, which is to identify knowledge gaps, scope a body of literature, or clarify concepts, without any methodological quality assessment and integrative synthesis of the included studies [22]. This integrative review was performed in accordance with the methodology of Whittemore and Knafl [21], and the results, were applicable, were reported according to the Preferred Reporting Items for Systematic review and Meta-Analyses (PRISMA) [23]. The protocol of the integrative review was not registered in a database and involved secondary 
analysis of data already published in the literature. Therefore, the present study was exempt from medical ethical review.The objective and main research questions of this integrative review were guided by a Population - Concept - Context (PCC) mnemonic [24]. The population was parents, families, and/or caregivers of children with cancer, and children/adolescents with cancer themselves; the concept was the information and communication needs regarding CAM; and the context was studies of both quantitative and qualitative methodology in all types of settings. The objective of this integrative review was to identify and describe the information and communication needs of parents of children with cancer, and children/adolescents themselves, regarding CAM. The integrative review questions were: 1 . Which information needs can be identified for parents of children with cancer, and/or their children? 2. Which sources do parents of children with cancer, and/or their children use to obtain CAM cancerrelevant information? 3. What needs do parents of children with cancer, and/or their children have regarding communication about CAM?

\section{Eligibility criteria}

Eligibility criteria for inclusion and exclusion of studies were defined according to the PCC mnemonic:1. The studies included described the perspective of the parents, families, and caregivers of children with cancer, as well the perspectives of children/adolescents with cancer up to 18 years. Studies describing the perspective of healthcare professionals or CAM providers were excluded.2. The studies included described how to search and find information on CAM regarding childhood cancer and CAM information needs.

3. The studies included described the needs to communicate about CAM regarding childhood cancer with healthcare professionals, CAM providers, friends, and relatives. Studies that described information and communication needs regarding cancer in adults were excluded, as well as studies that reported solely about the patients' and/or parents' disclosure of CAM use (without any study data) to health care professionals.

Different quantitative and qualitative research methodologies were included such as experience reports, surveys, expert opinions, individual and group interviews, and guidelines. Studies describing all type of cancers and stages of cancer, including treatment phase, post-treatment, and palliative phase, and in all settings were included. Studies included could be published in the Danish, Dutch, English, German, Norwegian, and Swedish languages. Since authors of this integrative review had excellent understanding of these six languages, translation of included studies was not necessary. Studies that were available only in the form of abstracts or notes were excluded. Searches were not restricted to any time/date.

\section{Information sources and search strategy}

Searches were performed by a health sciences librarian and the first author in the following databases: AMED, CAMbase, CINAHL (Ebsco), EMBASE, PubMed and PsycInfo. The German publishers Theme eJournals and Karger were also searched for studies. To identify additional studies not found by electronic searches, the reference lists of articles were checked. Depending on the database, abstracts and keywords were searched and various combinations of medical subject headings (MESH) terms and keywords were used, such as neoplasms, paediatrics child, adolescents, puberty, young adult, alternative therapies, complementary therapies, communication, information, information needs, dialogue, patient education, physician-patient relations, and dietary supplements. They were combined with "OR" and "AND" (the search-strings are attached as additional information). Keywords were adapted for the other electronic databases according to the specific subject headings or structure (see supplementary file).

\section{Study selection and data management}

Search results were uploaded in the reference manager program Endnote to facilitate study selection, and a single data management file was produced of all references identified through the search process. Duplicates were removed and two authors screened the remaining references independently. Two authors read the included articles and extracted the data, Disagreements between the authors were discussed and solved. In two cases of disagreement between the authors, additional information from study corresponding authors was sought on the basis of which it was decided that the articles did not meet the inclusion criteria. Reasons for excluding articles were documented. Neither of the review authors was blind to the journal titles, study authors, or institutions. A flowchart of the study selection and identification according to the (PRISMA-P) guidelines [23] was generated (see Fig. 1). Two authors read the articles and extracted the data. Data was extracted from all included articles using a pre-defined data charting form. Data extracted was study characteristics such as subject of the study, methodology, study design, aim, participants, sample size, inclusion and exclusion criteria, main findings, and funding of the study.

\section{Appraisal of study quality}

Critical appraisal tools from the Joanna Briggs Institute were used to assess the methodological quality of the included cross-sectional studies [25] and expert opinions [26]. Qualitative studies were assessed using the 10question appraisal tool from the Critical Appraisal Skills Program (CASP) checklist [27]. The criteria used to critically appraise the quality of each study design are 


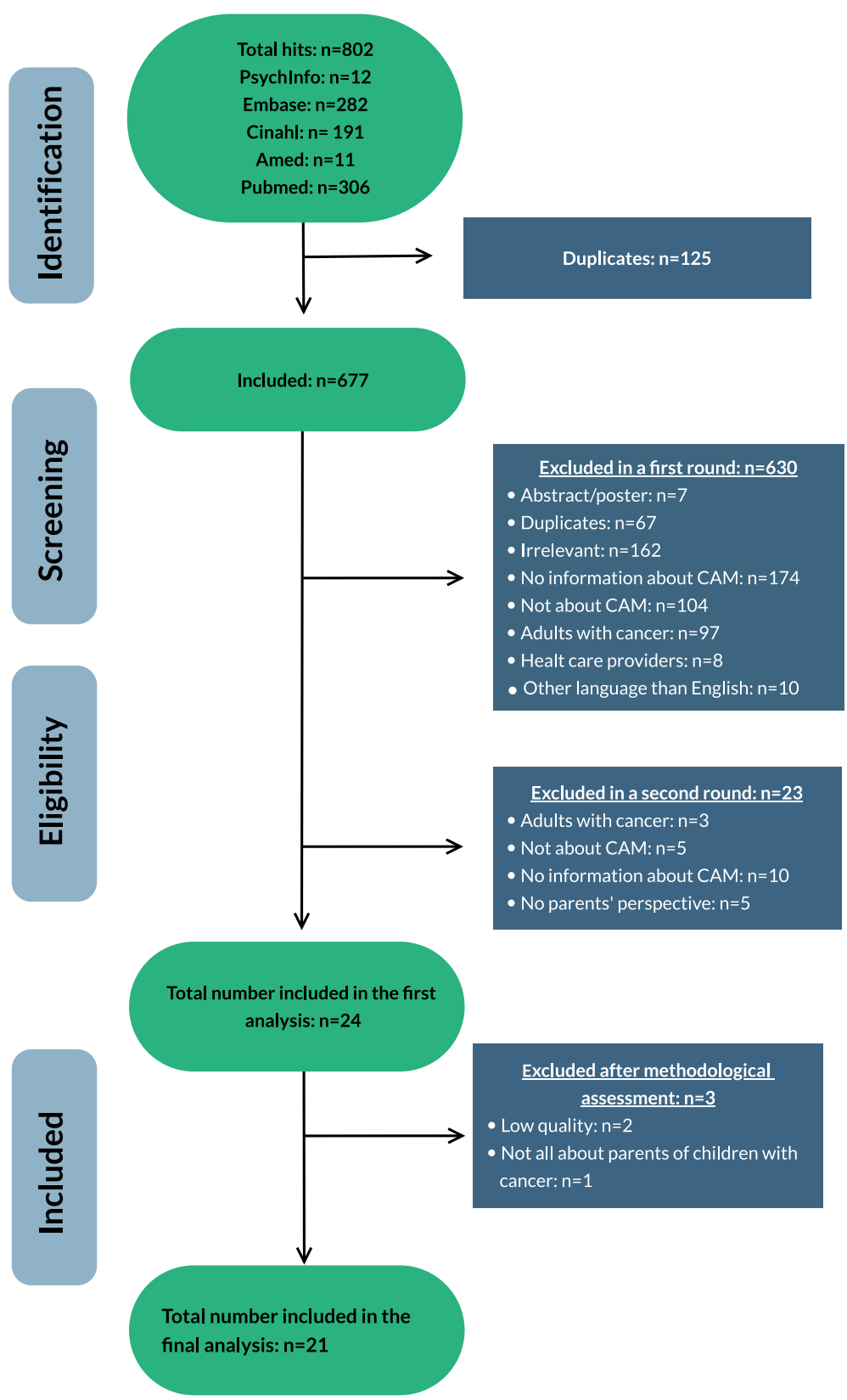

Fig. 1 Flow chart of the inclusion process in this study

described in Table 2. Two review authors conducted study quality assessment, and discrepancies between the authors' assessments were discussed and resolved. A table was generated for each quality item among all studies with the same design.

\section{Data synthesis}

The extracted data was analyzed according to the stages as described by Whittemore and Knafl [21], using a mixed methods synthesis [50]. First, primary source data was divided by three study designs (cross-sectional studies, expert opinions, and qualitative studies), and a segregated synthesis analysis per design was performed. Data reduction was performed on predetermined thematic categories (deductive) and new appearing categories (inductive) that were relevant for the review question. Predetermined thematic categories were risk perception (risk/benefit of CAM), direct risk situations (adverse effects/ negative interactions of CAM), indirect risk situations (ethical, disease causality, and treatment philosophy), risk communication (ineffective provider-patient relationship, delay, decline conventional medicine, how to talk about the use of 
CAM), and information regarding CAM (lack of knowledge about CAM, where do patients gather information, unmet information needs). These categories derived from a previously performed study on perception and communication among conventional and complementary health care providers involving cancer patients' use of CAM [51]. An additional predetermined thematic category, informed decision making, derived from a previous study on effective communication about the use of CAM in cancer care [52].

The next step was data display, converting data from individual sources into a matrix display to assemble data from multiple sources around the three study designs. Subsequently, quantitative data was translated to qualitative data to allow for a mixed methods synthesis. Constant data comparisons between the three display matrixes resulted in sub-themes and main emerging themes. The emerging themes were categorized into a table format, and discernment of main themes and sub-themes were verified with the primary source data for accuracy and transparency. Two review authors extensively discussed the outcome of each stage in the analysis process as to agree on emerging themes. Both review authors had previous experience with interviewing parents of children with cancer concerning their information and communication needs on CAM. However, both authors were aware as to not let their previous research experience affect the objectivity of data analysis and result interpretation. A record was kept during the stages of analysis as to document all thoughts, patterns, relationships, and interpretations made.

\section{Results}

\section{Searches}

The literature searches resulted in 802 potentially relevant studies (Fig. 1). All abstracts were screened for relevance using Endnote version X9 and the Annotated reference style. The Endnote program allowed the researcher to read the abstracts, exclude duplicates $(n=125)$, and put the studies into different categories of relevance. A total of 630 studies were excluded in a first round due to irrelevance $(7$ studies were abstracts, 67 studies were duplicates, 162 studies were irrelevant, 174 had no information about CAM, 104 studies were not about CAM, 97 studies included adults with cancer, 8 studies included health care providers, 10 studies were in languages other than English, German, Dutch, Swedish, Danish, and Norwegian, and 1 study used the same data set as another included study). In a second screening round, 23 studies were excluded (3 studies included adults with cancer, 5 studies were not about CAM, 10 studies had no information about CAM, 5 studies had not included the parents' perspective). A total of 24 studies (Fig. 1) were included in this review [10, 18, $28-49], n=16$ surveys $[10,18,28-41], n=5$ expert opinions [42-46], and $n=3$ qualitative studies [47-49].
The characteristics of included studies are tabulated in Table 1.

\section{Assessment of methodological quality/critical appraisal}

Five $(n=5)$ cross-sectional studies were assessed as low risk of bias as they had addressed nine out of nine items in its design, conduct, and analysis [31, 34, 38, 40, 41] (see Table 2). Three cross-sectional studies $(n=3)$ [10, $18,28]$ addressed eight items, six studies $(n=6)[30,32$, $33,35-37]$ addressed seven items, one study $(n=1)$ [29] addressed six items, and one study $(n=1)$ [39] addressed only four out of nine items. Three $(n=3)$ expert opinion papers $[42,45,46]$ were assessed as low risk of bias as they had addressed all six items in its design, conduct, and analysis. Two expert opinion papers $(n=2)[43,44]$ had addressed five out of six items. One qualitative study $(n=1)$ [48] was assessed with low risk of bias as it had addressed eight out of ten items in its design, conduct, and analysis. One study $(n=1)$ had addressed six items [49] and one study $(n=1)$ [47] addressed only four out of ten items. Of $n=24$ studies, $n=12$ were rated as high methodological quality (low risk of bias), $n=10$ were rated as medium methodological quality, and $n=2$ were rated as low methodological quality.

\section{Exclusion of studies for further analysis}

Three $(n=3)$ out of the 24 included studies were excluded from further analysis [29, 39, 47]. The article of Ball et al. [29] was about the use of dietary supplements by children with a chronic illness. However, only $20 \%$ of the total respondents were parents of children with cancer. Therefore, the results cannot be generalized to communication and information needs of parents of children with cancer specifically. The studies of Rajanandh and Bold et al. [39, 47] were excluded from further analysis due to low methodological quality and thereby high risk of bias (see Table 2). Therefore, twenty-one studies were used for further analysis in this review (see Fig. 1).

\section{Main themes}

The data was organized in five main themes. Three of the five emerging themes directly related to the three integrative review questions: Information on CAM (review question 1), sources of CAM information (review question 2), and communication about CAM with four sub-themes (respect, decline of conventional medicine, hope and control, disclosure of CAM use) (review question 3). Another emerging theme that related to review question 1 was informed decision-making on CAM. The fifth main theme observed was risk/benefit of CAM. "CAM use" refers to the use of CAM among children with cancer. 


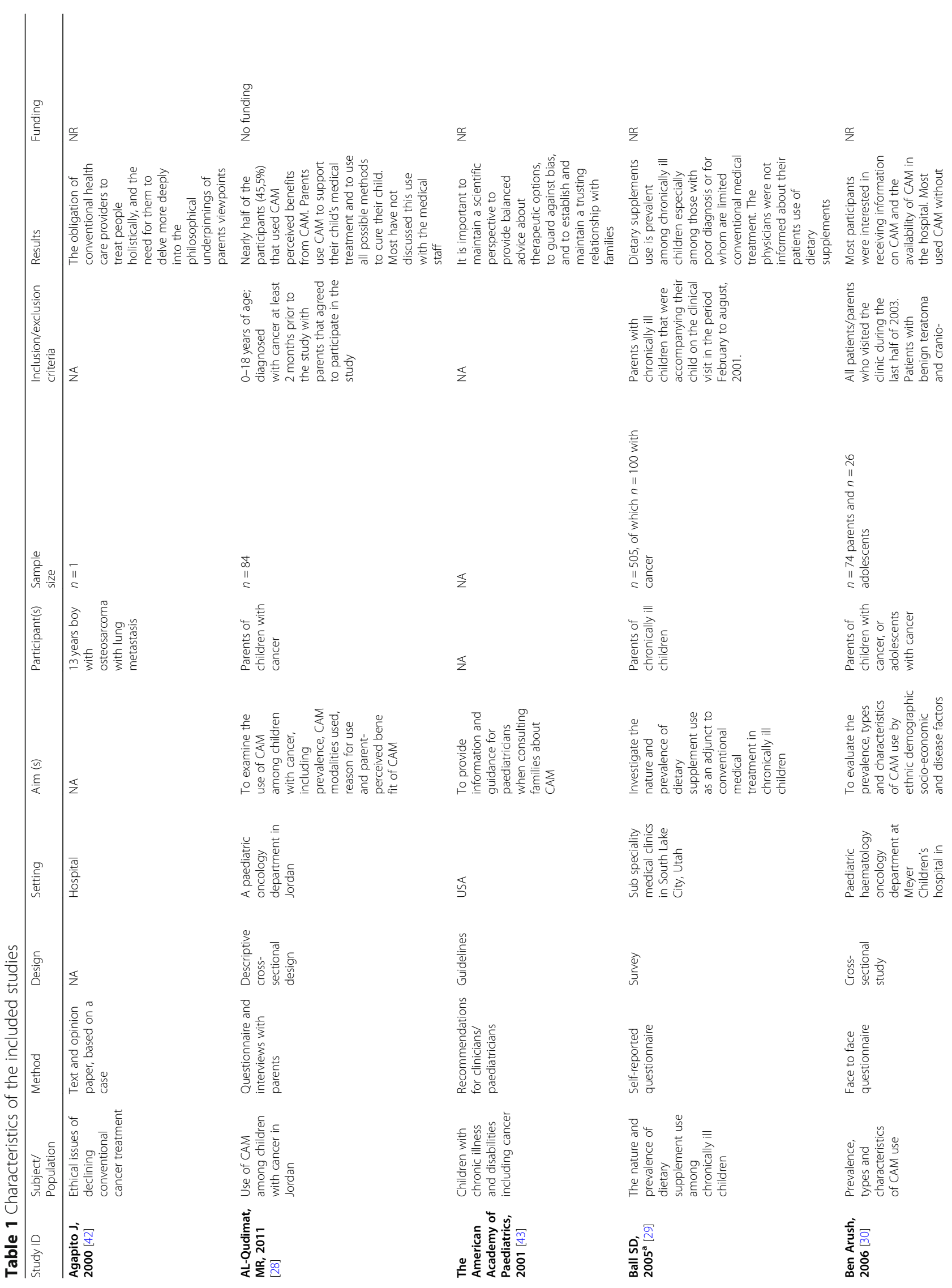




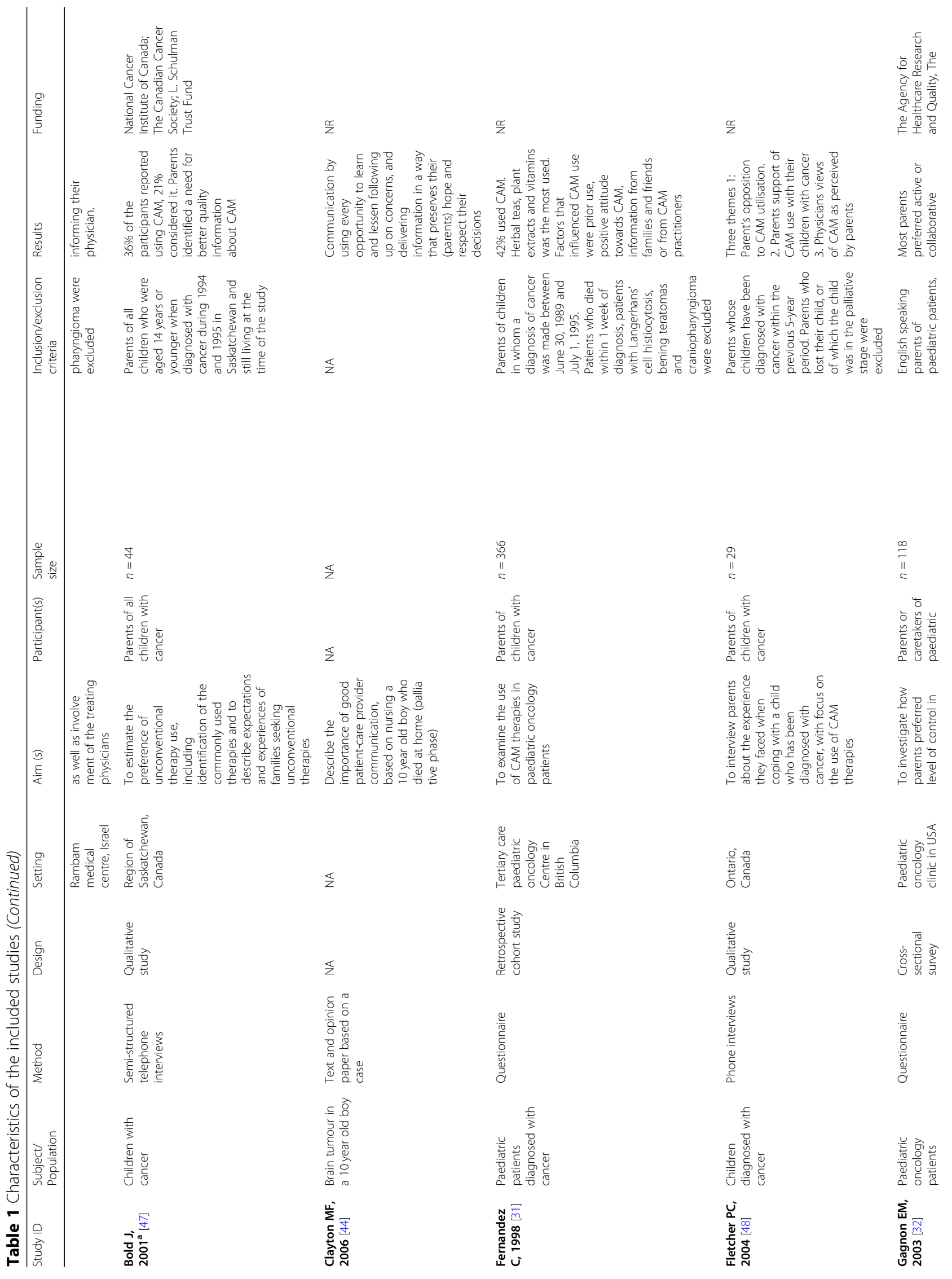




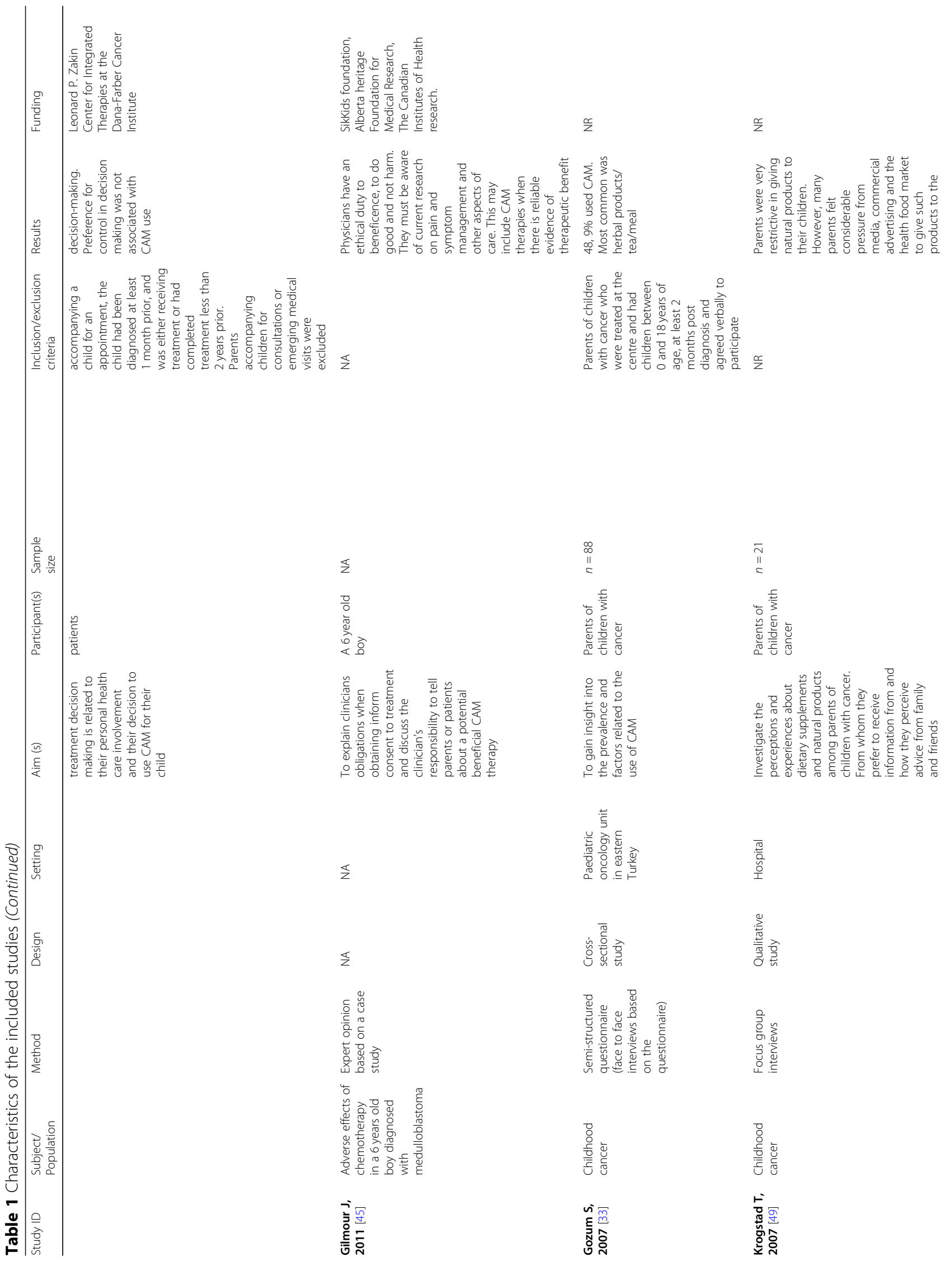




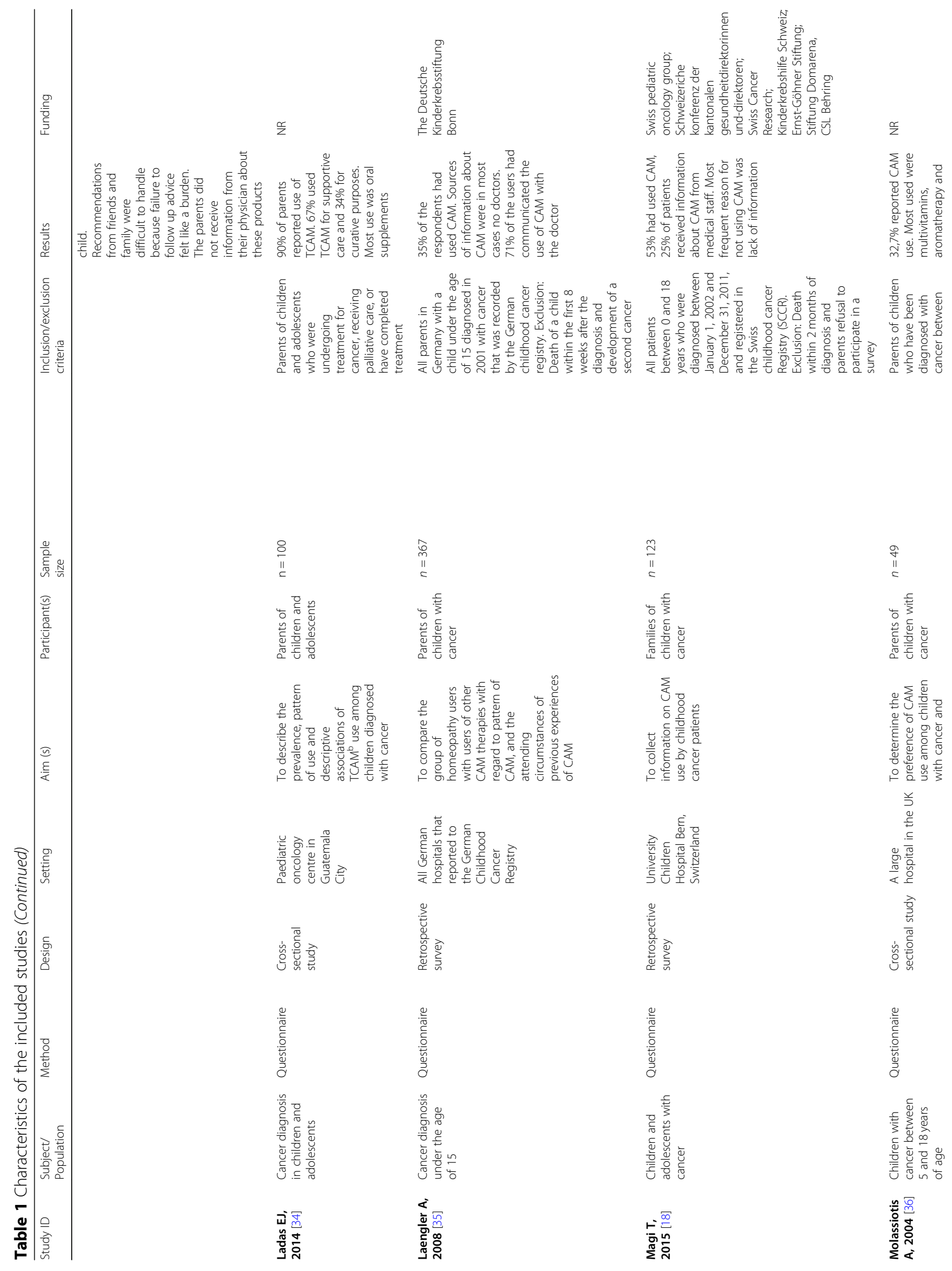


Stub et al. BMC Complementary Medicine and Therapies

(2020) 20:90

Page 10 of 19

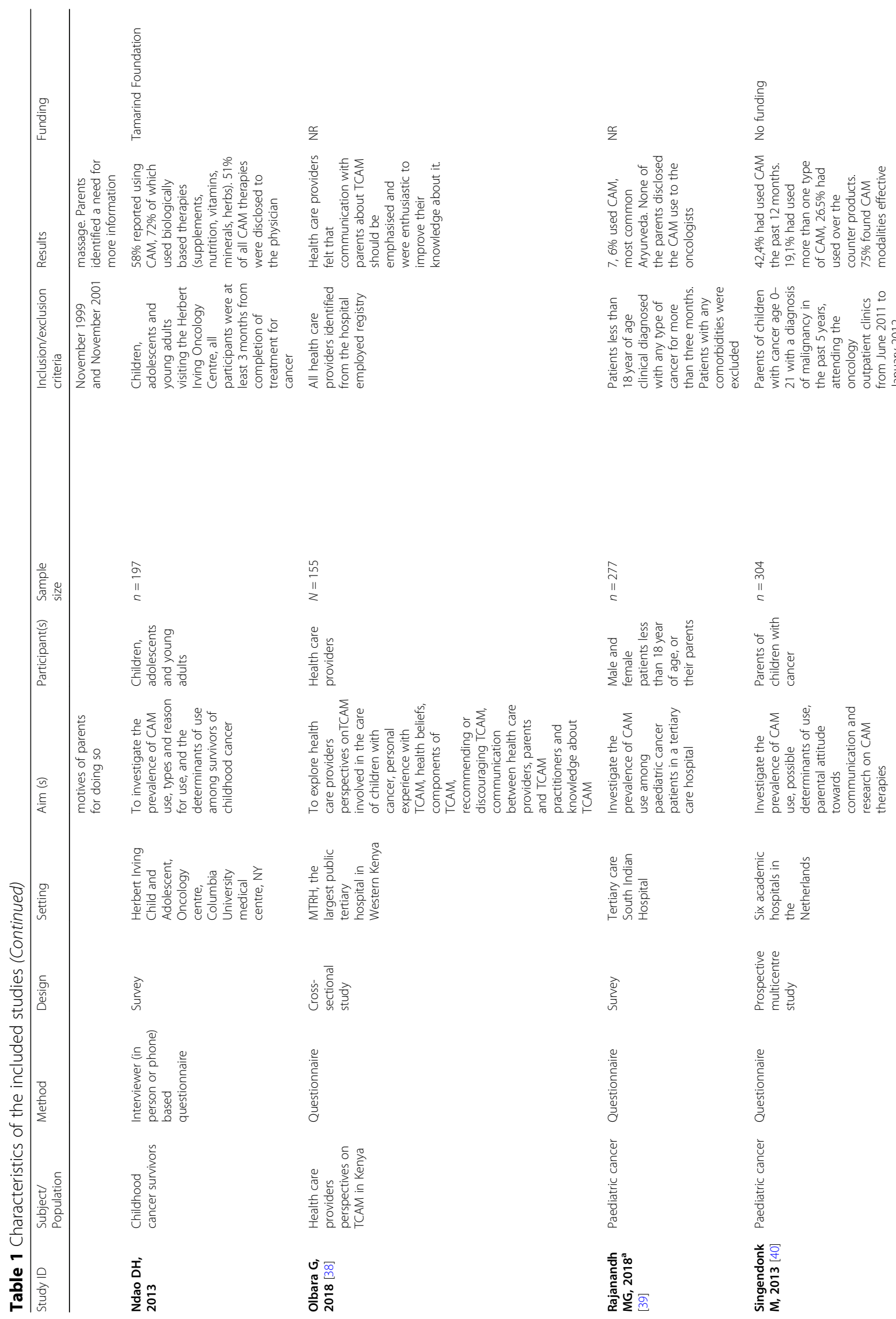




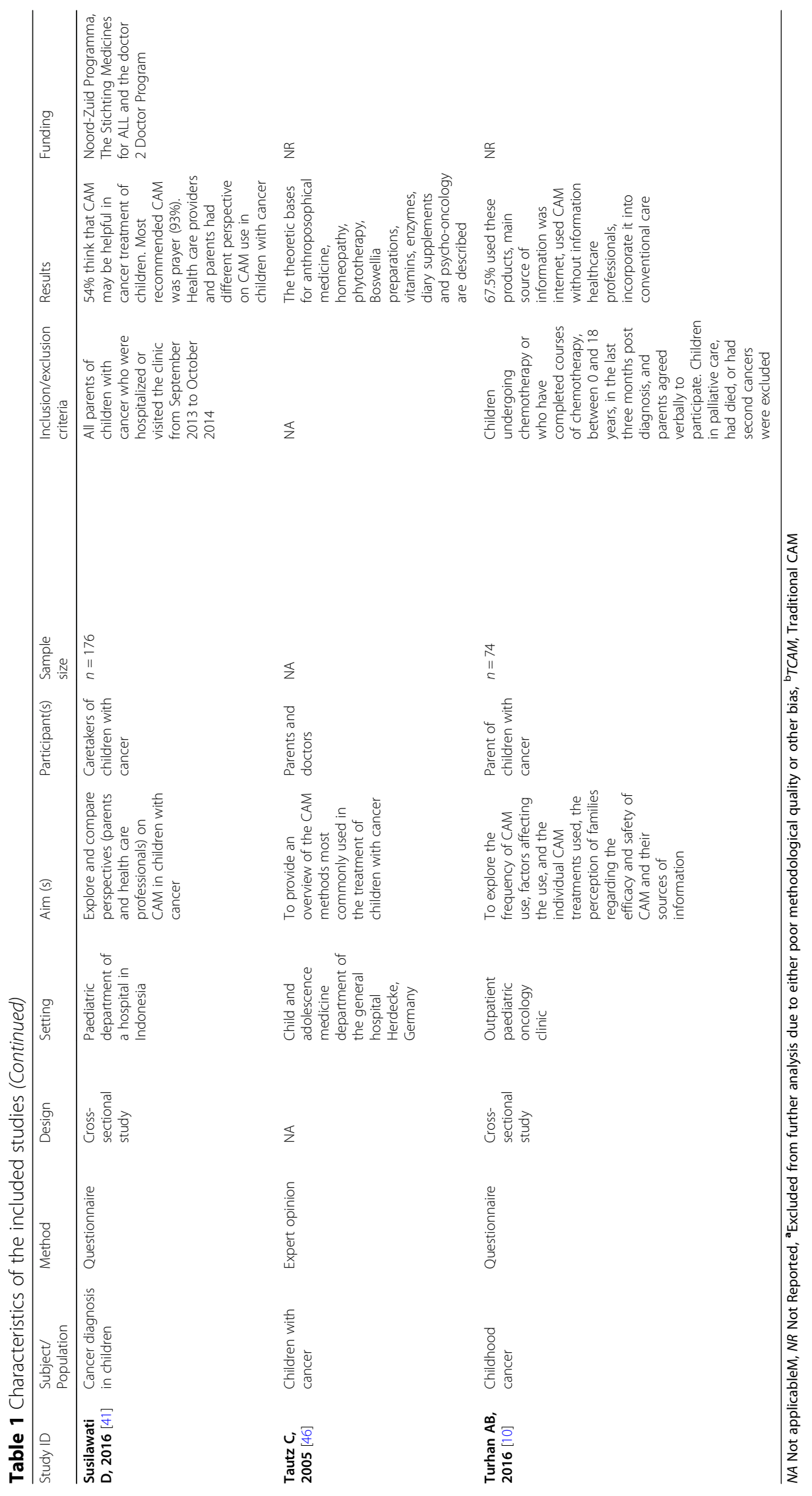




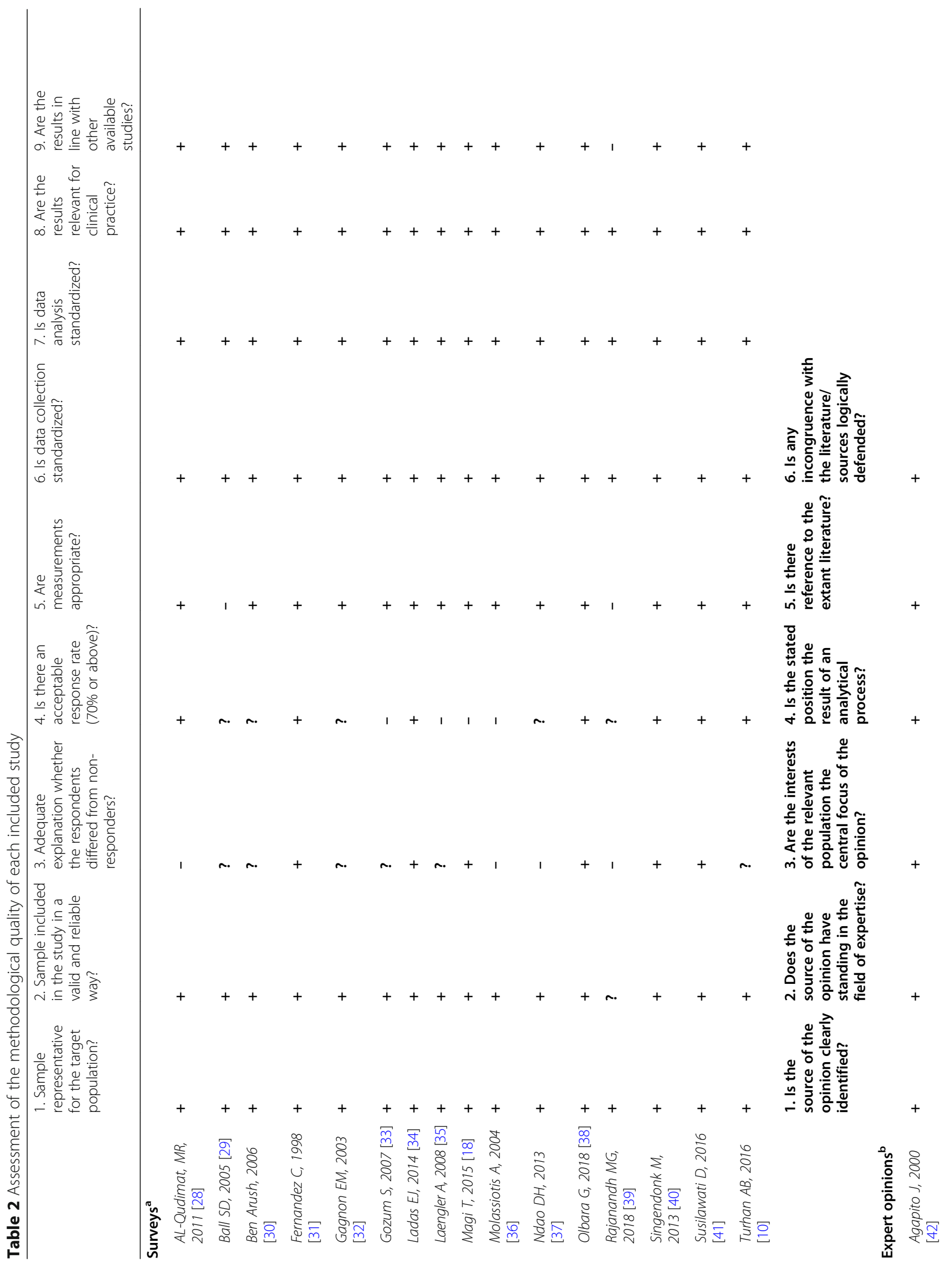




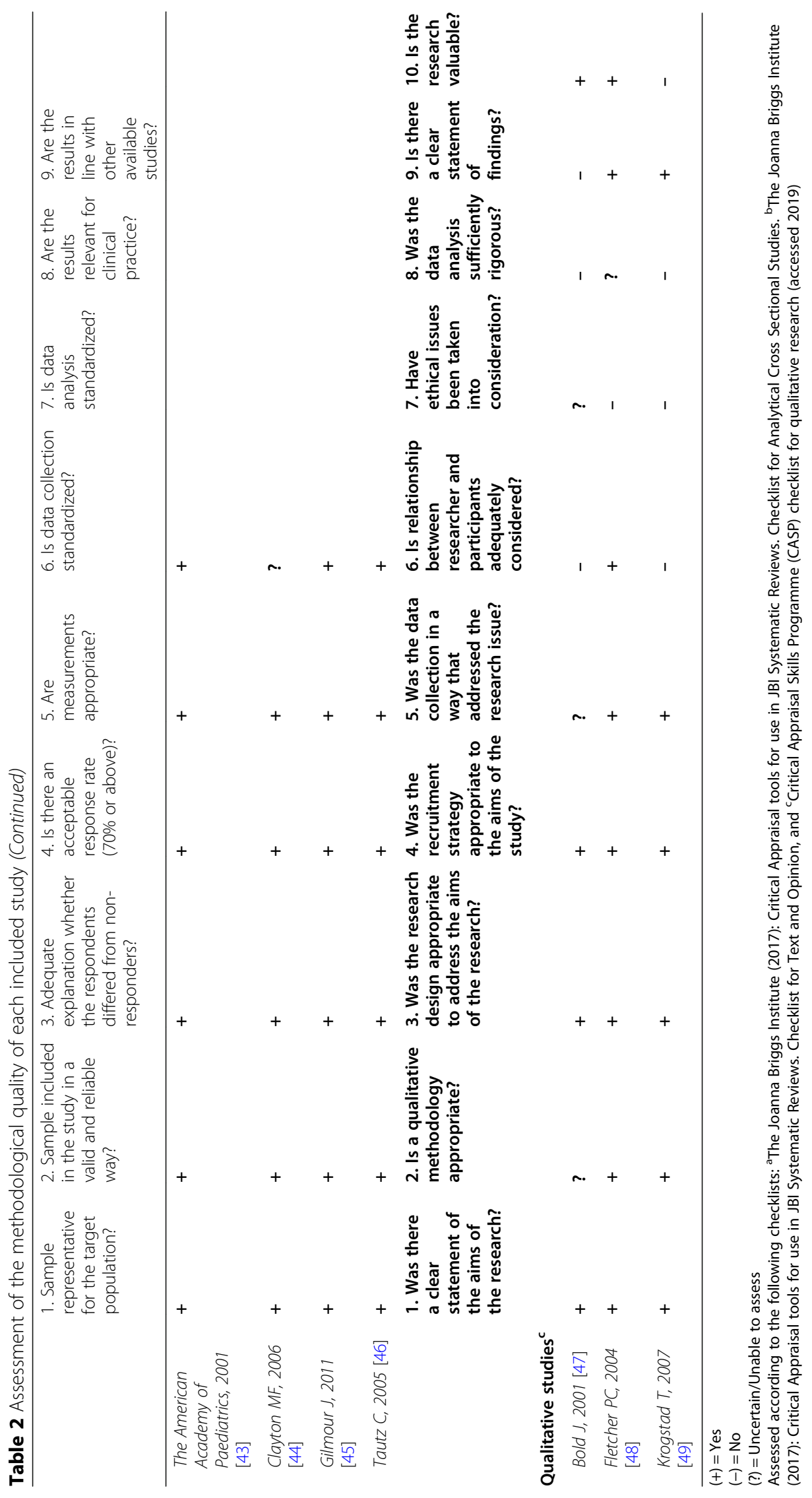




\section{INFORMATION on CAM}

Having a child with cancer is time consuming and many parents do not have the time to find reliable information about CAM. This review found that there is an apparent need among parents of children with cancer for information on CAM [40]. Fernandez [31] and Molassiotis et al. [36] reported that the most common reason for not using CAM was lack of information. In a survey, BenArush et al. [30] found that the majority of the parents were interested in obtaining more information and guidance about CAM.

Many parents wanted information on CAM from authoritative sources such as the oncologist or hospital where they are treated. Singendonk et al. [40] reported that parents wanted information on CAM to be provided by the treatment oncologist and offered in the hospital. If CAM treatment had been offered in the hospital, they would have considered it for their child [30,36]. This is in accordance with a Norwegian study where the parents would have liked to receive information from the hospital staff or the physician [49]. They would also have liked to receive information from the pharmacist, because they believed this was a more impartial source. This is in line with Fletcher et al. [48] who found in a qualitative interview study that parents wanted information about CAM integrated in the services they already received in the hospital, as lack of time hindered them to examine CAM modalities themselves.

Susilawati et al. [41] acknowledged that parents know little about CAM. This study found that the majority of the parents reported that their knowledge about the safety and efficacy of CAM was inadequate, and they wanted to learn or read more about it.

\section{Sources of CAM information}

Many parents want CAM information that is easily accessible, preferably from authoritative sources. However, according to nine studies $(n=9)$, the sources of information about CAM were mostly (i) family and friends, (ii) health care providers (CAM and conventional), and (iii) the media [10, 31, 33, 35-37, 45, 49]. (i) Family and friends: Fernandez et al. [31] reported that parents of children with cancer received information on CAM from families and friends. This is in accordance with Gozum et al. [33] who reported that most parents in Turkey learn about CAM from friends and relatives or other families with children who have cancer. According to Gilmour [45], the reason for using family and friends as the main source of information was that they did not receive CAM information from the oncologists. Children and young adults attending an oncology clinic in New York received information from their parents [37]. Krogstad et al. [49] found that parents received information about supplements/herbs from friends, families, commercials, and natural health food stores. The parents were, however, sceptical towards commercials regarding these products. They regarded information from families and friends trustworthy, but their advice felt like a burden because of failure to follow up. This was also the case for families in Turkey where the most frequent source of information about CAM reported by families was the Internet and relatives [10]. Family and friends were also the main source of information for the majority of the parents in Germany [35] and the UK [36].

(ii) Health care providers (CAM and conventional): In addition to the parents, children and young adults attending an oncology clinic in New York also received information from integrative providers [37]. In Germany [35] the source of information about CAM was in most cases health care providers other than doctors. Fernandez et al. [31] who investigated the use of CAM reported that the factors that influenced the CAM use were prior CAM use and positive attitude towards CAM, in addition to information from CAM providers. Molassiotis et al. [36] reported that health care providers were the second most commonly used source of information in the UK. However, in Switzerland Magi et al. [18] found that patients mainly received information on CAM from the medical staff at the University hospital in Bern. In addition, Ladas et al. [34] reported that a source of information about TCAM in Guatemala City was doctors and health care professionals.

(iii) The media: Even though many parents wanted information on CAM from reliable sources, they often used less reliable sources such as the media. Fernandez and Thuran et al. $[10,31]$ reported that one third of the participants in their study received information from this source. This was in line with Laengler and Ndao et al. [35, 37] who found that the media was one out of three sources where parents gathered information on CAM. Molassiotis et al. [36] reported that the parents identified a need for more information and that the media was the most commonly used source of information.

\section{Communication about CAM}

For better quality of care, communication about CAM use is needed between parents of children with cancer and their conventional providers. According to the American Academy of Paediatrics, CAM may improve the quality of life and address specific concerns of the child and family regarding cancer [43]. Therefore, a conversation about CAM may avert feelings of frustration and powerlessness that impel families to these modalities.

Respect Health care providers provide ethical care by respecting parents' choice on using CAM for their child. They have an ethical obligation to do good, and respect 
the parents' needs to try everything for their child. A team of nurses managed to maintain open communication with a mother of a severely ill son [44]. The mother informed them about the supplements the boy used, and the nurses were able to anticipate adverse interactions with other medications. She responded to the nurses' willingness to listen by keeping them informed about her son's CAM treatment.

Decline of conventional medicine. Autonomy and the role of the family to decide treatment for their child are vital ethical dilemmas when it comes to declining conventional medicine. These issues must be handled with care by health care providers and the government, as different philosophic worldviews between parents and health care providers may lead to a decline of conventional medicine [42]. Agapito described a case where the social services department went to court to protect a 13year-old boy from his father's influence. The family was religious and believed that faith alone could save him. The boy rejected conventional medical care, and the social services went to court to overrule this decision. During the legal process, the boy was diagnosed with lung metastasis and the case was dropped. Consensus regarding the choice of treatment can usually be reached, but it requires time and willingness to communicate. However, the decision to go to court created a communication barrier with the family and thereby the valuable consensus and share purpose usually found between health care providers and their patients and families broke down [42]. Agapito pointed out the ethical obligation of conventional health care providers to treat people holistically and do good [44]. They need to delve more deeply into the philosophical underpinnings of the parents' viewpoints.

Hope and control The importance of keeping hope alive when the child is serious ill is important. Loss of hope creates despondency or desperation, and parents need to maintain some sense of control over life, and hope against possible death of their child. Health care providers provide ethical care by respecting parents' choice on using CAM for their child [44]. The importance of keeping hope alive when the child was serious ill was addressed by three studies in this review [28, 42, 44]. To maintain hope, parents often perceived CAM safer and more efficient than research demonstrated, as to have rationale for trying all possible treatment methods for their child [28, 44]. Information about CAM gave a sense of control of the child's treatment for the parents. It also provided additional ways of helping their child to get through his/her cancer treatment. Moreover, it gave parents the feeling that they were doing everything possible to support their child's recovery [36]. Gagnon and
Recklitis [32] investigated how the parents' preferred level of control in treatment decision making was related to their personal health care involvement and their decision to use CAM for their children. They found that most parents using CAM preferred active or collaborative versus passive decision-making. Preference for control in decision-making was not associated with CAM use.

Disclosure of CAM use This review found that patients want an open and non-judgmental communication about CAM with their health care provider. Qudimat et al. [28] reported that a minority of CAM users discussed the use of CAM with their health care providers. The reason for non-disclosure was that the parents thought it was not important. Others thought they would receive negative reactions from the physician, and a few stated it was because the doctor did not ask. Gozum et al. [33] reported that one third of the CAM users discussed the topic with doctors and nurses and that the majority did not. Ben-Arush [30] reported that more than half of the CAM users had never consulted or discussed CAM use with any of their physicians, oncologists, or nurses. Half of the participants, who asked the physician about CAM, reported that the physicians encouraged CAM use or proposed a consultation with a physician well trained in CAM. A minority decided not to use CAM even though they asked for advice. The health care providers raised the issue of CAM in only four cases. Singendonk et al. [38] found that in the majority of the cases the parents initiated the discussion about CAM use. The reactions from the health care providers were impartial or positive, and none had experienced negative reactions. Magi et al. [18] reported that more than half of the parents reported to have told the attending oncologist about CAM. Laengler et al. [35] found that most parents spoke to a doctor about the use of CAM. This is in accordance with Fernandez et al. [31] who reported that only a few of the parents were uncomfortable discussing CAM with their oncologist. The majority of the parents felt that their oncologist had no opinion about CAM or had not made their opinion known. Susilawati et al. [41] found that half of the parents would not raise the topic of CAM if they perceived the doctor as sceptical. Despite caution and scepticism, doctors should facilitate an atmosphere of openness in the consultation so that the patients feel comfortable discussing CAM. The parents perceived that a more open doctor-parent communication about CAM might enhance the doctor's knowledge of which CAM modalities patients were using.

According to a study by Fletcher et al. [48], parents emphasized that the physicians should be receptive to CAM to obtain support for their choice. The health care providers, on the other hand, were cautious about CAM 
use during conventional cancer treatment and wanted to be informed prior to the administration of CAM. Then they could determine whether the modalities in question were appropriate. According to the parents, the physicians advised them not to initiate any treatment without informing their health care team. Krogstad et al. [49] found that if parents asked the physicians about possible use of multivitamins for the child, the physicians answered that they should decide themselves. Ndao et al. [37] reported that the disclosure rate of CAM use among children and adolescents to the physician increased from 1998 to 2008. According to the American Academy of Paediatrics [43], clinicians should listen carefully and acknowledge the families' concerns, priorities, and fears, including social and cultural factors. They must continue to care for the family even though they choose to use CAM. This is in line with Gilmore [45] who pointed out the physician's obligation to do good, and be updated on beneficial CAM treatment options.

\section{Informed decision-making on CAM}

It is important that parents get easily accessible and reliable information about CAM to make informed decisions about these modalities. Agapito and Fernandez pointed out the importance of autonomy of the family when making treatment decisions for children [31, 42]. Adequate understandable information may empower parents and give them freedom to act on that information [31]. Clyton [44] disclosed a story about a mother who preferred to make decisions about CAM independently after receiving information from the health care team. Molassiotis et al. [36] argued that doctors and nursing staff should offer and discuss CAM with parents so that they are able to make informed decisions and that CAM literature should be available at the ward. This is in line with Tautz et al. [46] who reported that to support parents in decision making, the doctor needs to build a trustworthy and resilient relationship with the parents. They must do that without judgement. To make informed consent, parents should be informed about the placebo effect and the need for conducting controlled studies. Tautz et al. [46] proposed to make a decision aid with scientific content because there is lots of information out there that is hard to assess for the parents.

\section{Risk/benefit of CAM use}

Many parents hold the belief that in order to use CAM for their children, the modalities should be absolutely safe and beneficial. A six-year-old boy with medulloblastoma experienced adverse effects of chemotherapy. The boy received acupuncture that helped relieve chemotherapy-related vomiting. Based on this case, Gilmore [45] discussed the clinician's responsibility to inform the parents or patients about potential beneficial CAM modalities for adverse effects of conventional cancer treatments. According to Tautz et al. [46], many parents fear the consequences of conventional cancer treatment for their child and raise the need for information on supportive CAM modalities. The parents in this study wanted to know whether CAM was safe, had less adverse effects, and was equally effective compared to conventional medicine. According to the Academy of American oncologists, parents should be advised about the indirect harm that may be caused by the financial burden of CAM and other unanticipated costs, such as the time investment required to administer the modality [43].

\section{Discussion}

\section{Summary of evidence}

This review demonstrates that parents of children with cancer want high quality and reliable information on CAM from authoritative sources provided at the hospital where their children are treated. Parents want this information primarily from conventional health care personnel. They emphasize autonomy for the family when making CAM treatment decision for their children. To have some sense of control of their children's recovery and do everything possible for them, they demanded unbiased information from scientific sources to act freely on that information. In addition, they wish an open, non-judgmental conversation about CAM with the attending physician or oncologist who respect their choice. To provide ethical care and prevent decline of conventional cancer treatment, conventional health care providers need to update their knowledge about CAM, discuss risks and benefits of CAM with parents and be aware of the philosophical underpinnings of the parents' viewpoints.

\section{Limitations}

This integrative review must be read in light of its limitation, which largely concerns the search methodology such as the keywords and MESH term used, language limitations and scope. Generally, the variation in key terms and concepts regarding parents' information and communication needs on CAM may have possibly missed some relevant papers pertinent to the study. Likewise, limiting studies to English, German, Dutch, and the Scandinavian languages could have missed useful papers in other languages. However, the combination of a clearly articulated (PCC) mnemonic and search methods, including a research librarian in the research team and reviewing articles with multiple experts, as well as applying critical appraisal tools to measure the methodological quality, contributed to counteract the obvious limitations of performing a systematic review. Another limitation of this review is the inclusion of studies with varying designs and study quality, which may have affected the study outcome. However, the 
integrative design of this review allowed for inclusion of studies of different designs, and studies of low quality were excluded from this integrative analysis.

\section{Conclusion}

In this integrative review, the communication and information needs on CAM of parents who have children with cancer were systematically investigated. Of 24 included papers, 21 were of medium to high quality and therefore of potential use to inform paediatric oncology policy, clinical practice, and stakeholders in the field. The five main themes identified were consistent within the theories of Frankel and Stub on risk communication and information on CAM use in cancer care [52, 53], namely, information, communication, and informed decision-making.

\section{Information}

Parents wanted to know whether CAM was safe, had less adverse effects, and was equally effective compared to conventional medicine. However, they mostly obtained CAM information from less authoritative sources such as family, friends, and the media. They expressed a need for good quality information from evidence-based sources provided at the hospital where their children received treatment (oncologists, physicians, or nurses). Many CAM modalities have not been investigated in a rigorous scientific manner and information available in the medical literature on CAM use may be inaccessible and difficult to interpret for the lay public [31]. Moreover, adverse effects of CAM and interaction with conventional care have been reported [54-56]. Advance status of the child's disease, high risk of death at diagnosis, and influence of family and friends are significant factors in choosing CAM and may also mitigate against a truly free choice [31]. Despite these concerns, few parents in this review perceived the quality of life of their child to be compromised by using CAM, in fact most of them felt that it had improved. The American Academy of Paediatrics [43] recommends clinicians to guide parents and help them seek and assess the merits of specific CAM modalities.

\section{Communication}

Parents emphasize an open communication about CAM with health care providers as this may avert feelings of frustration and powerlessness that impel families to these modalities. By respecting the parents' choice and their needs to try everything for their children, health care providers provide ethical care. However, healthcare providers may need to delve more deeply into the philosophical underpinnings of the parents' viewpoints, as fear of negative reactions from the treating oncologist/physician was found to be a major reason for parents to not disclose their children's CAM use. According to the American Academy of Paediatrics [43], clinicians should avoid dismissal of CAM in ways that communicate a lack of sensitivity or concern for the family's perspective. One should avoid angry and defensive reactions and seek ethical consultation in difficult cases. The refusal of conventional cancer treatment in favour of CAM is rare in Western countries, as these modalities are often used complementary [57]. Paediatricians from developing countries often face the challenge of convincing families who believe in the use of CAM alone [8].

\section{Informed decision-making}

Results from this review demonstrate that the autonomy of the family is important when making treatment decisions for children, as adequate understandable information may empower parents and give them freedom to act on that information [31]. It is therefore of vital importance that health care providers build trustworthy and resilient relationships with parents to support them in decisionmaking [46], something parents of children with cancer demands, according to data from this review. Providing health-related information to patients and their relatives can empower them to make informed decisions concerning prevention, screening, and treatment [58]. It is also regarded as an essential element of high quality care [59]. A systematic review from 2015 [59], that investigated the information needs independent of certain diseases in patients and relatives in Germany, found that information about cancer treatment and juvenile rheumatic arthritis were the most prominent topics of interest. Information on CAM and nutrition was also of high interest. In a study on the demand for CAM among cancer patients, almost half of the participants who were interviewed demanded consultations about CAM, irrespective of whether they already used CAM [60]. Only a minority was not interested in CAM.

\section{Implication for clinical practice and further research}

Based on the results of this integrative review, parents often receive advice from family and friends to choose CAM as supportive care for their children with cancer, to treat adverse effects of conventional cancer treatment or to promote quality of life and to possibly "cure" the cancer process itself. Parents express a need for high quality information on CAM from authoritative sources, preferably from healthcare professionals. These findings stress the importance to develop evidence-based decision tools on CAM use, to enable health care professionals and parents of children with cancer to make well informed, individual decisions concerning CAM. 


\section{Abbreviations}

CAM: Complementary and alternative medicine

\section{Acknowledgements}

We want to thank Jane Ekelund for technical support. The publication charges for this article have been funded by a grant from the publication fund of UiT The Artic University of Norway.

\section{Authors' contributions}

TS initiated the project and performed the database searches together with GO. TS and MJ performed the methodological assessment, screening of the studies and data extraction and analysis. TS, AEK and MJ contributed to conceptualization and design of the study. They revised the manuscript critically for important intellectual content. All authors read and approved the final version of the manuscript.

\section{Authors' information}

AEK is a language sociologist and a complementary therapist. She holds a $\mathrm{PhD}$ in Medical science and is trained in quantitative research design. MJ holds a PhD in Medicine and has considerable expertise in understanding the use of complementary modalities, and patient-provider communication about complementary therapy use. TS is trained in complementary medicine. She holds a PhD in Medical science and is specialized in both qualitative and quantitative research methodology. $\mathrm{GO}$ is a senior librarian and responsible for the training of students and researchers in literature search and Endnote at the Institute of Health Science at UIT the Arctic University of Norway.

\section{Funding}

This research was funded by the Children's Cancer Society Troms and Finnmark, Norway.

\section{Availability of data and materials}

NA

\section{Ethics approval and consent to participate}

NA

\section{Consent for publication}

NA

\section{Competing interests}

The authors declare that they have no competing interests.

\section{Author details}

${ }^{1}$ National Research Center in Complementary and Alternative Medicine (NAFKAM), Department of Community Medicine, Faculty of Health Sciences, UiT The Arctic University of Norway, Hansine Hansens veg 19, 9019 Tromsø, Norway. ${ }^{2}$ Science and Health Library, UiT The Arctic University of Norway, Hansine Hansens veg 19, 9019 Tromsø, Norway.

\section{Received: 11 September 2019 Accepted: 5 March 2020}

Published online: 17 March 2020

\section{References}

1. Cheng L, Liu F, Feng S, Wang Y, Gu Y, Kang Q. Symptom experience of children with Cancer younger than eight years of age: an integrative review. J Pain Symptom Manag. 2019;58(1):157-66.

2. Hedén L, Pöder U, von Essen L, Ljungman G. Parents' perceptions of their Child's symptom burden during and after Cancer treatment. J Pain Symptom Manag. 2013;46(3):366-75.

3. Pöder U, Ljungman G, von Essen L. Parents' perceptions of their Children's Cancer-related symptoms during treatment: a prospective, longitudinal study. J Pain Symptom Manag. 2010;40(5):661-70.

4. Ladas EJ. Integrative medicine in childhood Cancer. J Altern Complement Med. 2018:24:910-5.

5. Complementary, Alternative, or Integrative Health: What's In a Name? [ https://nccih.nih.gov/health/integrative-health\#hed1].

6. Bishop FL, Prescott P, Chan YK, Saville J, von Elm E, Lewith GT. Prevalence of Complementary medicine use in pediatric Cancer: a systematic review. Pediatrics. 2010;125(4):768-76.
7. Diorio C, Lam CG, Ladas EJ, Njuguna F, Afungchwi GM, Katherine Taromina K, Marjerrison S. Global use of traditional and Complementary medicine in childhood Cancer: a systematic review. J Glob Oncol. 2017;3(6):791-800.

8. Chotsampancharoen T, Sripornsawan P, Duangchu S, Wongchanchailert M, McNeil E. Survival Outcome of Alternative Medicine Treatment for Newly Diagnosed Acute Leukemia in Children. Acta Haematol Acta haematologica. 2018;140:203-8.

9. Buckner CA, Lafrenie RM, Dénommée AJ, Caswell JM, Want DA. Complementary and alternative medicine use in patients before and after a cancer diagnosis. Curr Oncol. 2018;25(4):e275-81.

10. Turhan AB, Bör Ö. Use of herbs or vitamin/mineral/nutrient supplements by pediatric oncology patients. Complement Ther Clin Pract. 2016;23:69-74.

11. Werneke U, Earl J, Seydel C, Horn O, Crichton P, Fannon D. Potential health risks of complementary alternative medicines in cancer patients. $\mathrm{Br} J$ Cancer. 2004:90(2):408-13.

12. Jermini M, Dubois J, Rodondi PY, Zaman K, Buclin T, Csajka C, Orcurto A, E Rothuizen L. Complementary medicine use during cancer treatment and potential herb-drug interactions from a cross-sectional study in an academic Centre. Sci Rep. 2019:9(1):5078.

13. Roth M, Lin J, Kim M, Moody K. Pediatric Oncologists' views toward the use of Complementary and alternative medicine in children with Cancer. J Pediatr Hematol Oncol. 2009;31:177-82.

14. Vlieger AM, van Vliet M, Jong MC. Attitudes toward complementary and alternative medicine: a national survey among paediatricians in the Netherlands. Eur J Pediatr. 2011;170(5):619-24.

15. Complementary and Alternative Medicine [https://www.cancer.gov/aboutcancer/treatment/cam].

16. Hargrave DR, Hargrave UA, Bouffet E. Quality of health information on the internet in pediatric neuro-oncology. Neuro-Oncology. 2006;8(2):175-82.

17. Ernst E, Schmidt K. 'Alternative' cancer cures via the internet? Br J Cancer. 2002:87(5):479-80

18. Magi T, Kuehni CE, Torchetti L, Wengenroth L, Luer S, Frei-Erb M. Use of Complementary and alternative medicine in children with Cancer: a study at a Swiss University hospital. PLoS One. 2015:10(12):e0145787.

19. Grant MJ, Booth A. A typology of reviews: an analysis of 14 review types and associated methodologies. Health Info Lib J. 2009;26(2):91-108.

20. Broome ME. Integrative literature reviews in the development of concepts. In: Rodgers BL, Knafl KA, editors. Concept development in nursing: foundations. Philadelphia: WB Saunders; 1993.

21. Whittemore R, Knafl K. The integrative review: updated methodology. J Adv Nurs. 2005;52(5):546-53.

22. Peters MDJ, Godfrey CM, Khalil HB, Mclnerney P, Parker D, Soares CB. Guidance for conducting systematic scoping reviews. Int J Evid Based Healthc. 2015;13(3):141-6.

23. Shamseer $L$, Moher $D$, Clarke $M$, Ghersi D, Liberati A, Petticrew M, Shekelle $P$ Stewart LA. Preferred reporting items for systematic review and metaanalysis protocols (PRISMA-P) 2015: elaboration and explanation. BMJ. 2015; 349:97647.

24. Reviewers' Manual 2015:Methodology for JBI Scoping Reviews [https:// joannabriggs.org/about_jbi/our_approach].

25. The Joanna Briggs Institute: Critical Appraisal tools for use in JBI Systematic Reviews. Checklist for Analytical Cross Sectional Studies.2017. http:// joannabriggs.org/research/critical-appraisal-tools.html.

26. The Joanna Briggs Institute: Critical Appraisal tools for use in JBI Systematic Reviews. Checklist for Text and Opinion. 2017. http://joannabriggs.org/ research/critical-appraisal-tools.html

27. Qualitative Research Checklist; [ https://casp-uk.net/wp-content/uploads/201 8/03/CASP-Qualitative-Checklist-2018_fillable_form.pdf].

28. Al-Qudimat MR, Rozmus CL, Farhan N. Family strategies for managing childhood cancer: using complementary and alternative medicine in Jordan. J Adv Nurs. 2011;67(3):591-7.

29. Ball SD, Kertesz D, Moyer-Mileur LJ. Dietary supplement use is prevalent among children with a chronic illness. J Am Diet Assoc. 2005;105(1):78-84.

30. Ben Arush MW, Geva H, Ofir R, Mashiach T, Uziel R, Dashkovsky Z. Prevalence and characteristics of complementary medicine used by pediatric cancer patients in a mixed western and middle-eastern population. J Pediatr Hematol Oncol. 2006;28(3):141-6.

31. Fernandez CV, Stutzer CA, MacWilliam L, Fryer C, Fernandez CV, Stutzer CA, MacWilliam L, Fryer C. Alternative and complementary therapy use in pediatric oncology patients in British Columbia: prevalence and reasons for use and nonuse. J Clin Oncol. 1998;16(4):1279-86. 
32. Gagnon EM, Recklitis CJ. Parents' decision-making preferences in pediatric oncology: the relationship to health care involvement and complementary therapy use. Psychooncology. 2003;12(5):442-52.

33. Gozum S, Arikan D. M B: Complementary and alternative medicine use in pediatric oncology patients in eastern Turkey. Cancer Nurs. 2007;30(1):38-44.

34. Ladas EJ, Rivas S, Ndao D, Damoulakis D, Bao YY, Cheng B, Kelly KM, Antillon F. Use of traditional and complementary/alternative medicine (TCAM) in children with cancer in Guatemala. Pediatr Blood Cancer. 2014;61(4):687-92.

35. Laengler A, Spix C, Seifert G, Gottschling S, Graf N, Kaatsch P. Complementary and alternative treatment methods in children with cancer: a population-based retrospective survey on the prevalence of use in Germany. Eur J Cancer. 2008;44(15):2233-40.

36. Molassiotis A, Cubbin D. 'Thinking outside the box': complementary and alternative therapies use in paediatric oncology patients. Eur J Oncol Nurs. 2004:8(1):50-60

37. Ndao DH, Ladas EJ, Bao Y, Cheng B, Nees SN, Levine JM, Kelly KM. Use of complementary and alternative medicine among children, adolescent, and young adult cancer survivors: a survey study. J Pediatr Hematol Oncol. 2013; 35(4):281-8.

38. Olbara G, Parigger J, Njuguna F, Skiles J, Sitaresmi MN, Gordijn S, de Ven P, Kaspers G, Mostert S, van de Ven P, et al. Pediatr Blood Cancer. 2018;65(12): e27309 N.PAG-N.PAG.

39. Rajanandh MG, Scott JX, Reddy JS, Raju JM, Kaniarivi M, Raj KR. Pattern of complementary and alternative medicine use in pediatric oncology patients in a south Indian hospital. J Cancer Res Pract. 2018;5(1):20-3.

40. Singendonk M, Kaspers GJ, Naafs-Wilstra M, Meeteren AS, Loeffen J, Vlieger A. High prevalence of complementary and alternative medicine use in the Dutch pediatric oncology population: a multicenter survey. Eur J Pediatr. 2013;172(1):31-7.

41. Susilawati D, Sitaresmi M, Handayani K, Ven P, Sutaryo KG, Mostert S HealthCare Providers' and Parents' perspectives on Complementary alternative medicine in children with Cancer in Indonesia. Asian Pac J Cancer Prev. 2016;17(7):3235-42.

42. Agapito J. Tyrell Dueck: ethical implications for radiation therapists. Can J Med Rad Technol. 2000;31(2):45-8.

43. American Academy of Pediatrics. Committee on children with disabilities: counseling families who choose Complementary and alternative medicine for their child with chronic illness or disability. Pediatrics. 2001;107:598-601.

44. Clayton MF. Living with illness. Communication: an important part of nursing care. Am J Nurs. 2006:106(11):70-2.

45. Gilmour J, Harrison C, Asadi L, Cohen MH, Vohra S. Informed consent: advising patients and parents about complementary and alternative medicine therapies. Pediatrics. 2011;128(Suppl 4):S187-92.

46. Tautz C, Langler A. Complementary and alternative medicine in children with cancer - the parents and the doctor's perspective. [German]. Padiatrische Praxis. 2005;67(3):451-62.

47. Bold J, Leis A. Unconventional therapy use among children with Cancer in Saskatchewan. J Pediatr Oncol Nurs. 2001;18(1):16-25.

48. Fletcher PC, Clarke J. The use of complementary and alternative medicine among pediatric patients. Cancer Nurs. 2004;27(2):93-9.

49. Krogstad T, Nguyen M, Widing E, Toverud EL. Children with cancer and their use of natural products. [Norwegian]. Tidsskr Nor Laegeforen. 2007;127(19): 2524-6

50. Pearson A, White H, Bath-Hextall F, Apostolo J. The Joanna Briggs institute reviewers' manual 2014: methodology for JBI mixed methods systematic reviews. Adelaid: The Joanna Briggs Institute; 2014.

51. Stub T, Quandt SA, Arcury TA, Sandberg JC, Kristoffersen AE, Musial F, Salamonsen A. Perception of risk and communication among conventional and complementary health care providers involving cancer patients' use of complementary therapies: a literature review. BMC Complement Altern Med. 2016;16(1):1-14.

52. Frenkel M, Cohen L. Effective communication about the use of complementary and integrative medicine in cancer care. J Altern Complement Med. 2014;20(1):12-8.

53. Stub T, Quandt SA, Arcury TA, Sandberg JC, Kristoffersen AE. Complementary and conventional providers in cancer care: experience of communication with patients and steps to improve communication with other providers. BMC Complement Altern Med. 2017;17(1):301.

54. Posadzki P, Alotaibi A, Ernst E, et al. Int J Clin Pract. 2012:66(12):1178-88.
55. Stub T, Musial F, Kristoffersen AA, Alræk T, Liu J. Adverse effects of homeopathy, what do we know? A systematic review and metaanalysis of randomized controlled trials. Complement Ther Med. 2016; 26:146-63.

56. Zhou X, Li CG, Chang D, Bensoussan A. Current status and major challenges to the safety and efficacy presented by Chinese herbal medicine. Medicines (Basel). 2019;6(1):14

57. Deng GE, Frenkel M, Cohen L, Cassileth BR, Abrams DL, Capodice JL. Evidence-based clinical practice guidelines for integrative oncology: Complementary therapies and botanicals. Soc Integr Oncol. 2009;7:85-120.

58. Iconomou G, Vagenakis AG, Kalofonos HP. The informational needs, satisfaction with communication, and psychological status of primary caregivers of cancer patients receiving chemotherapy. Support Care Cancer. 2001;9(8):591-6.

59. Pieper D, Jülich F, Antoine SL, Bächle C, Chernyak N, Genz J, Eikermann M, Icks A. Studies analysing the need for health-related information in Germany - a systematic review. BMC Health Serv Res. 2015;15:407.

60. Eustachi A, Pajtler H, Linde K, Melchart D, Weidenhammer W. Patients of an interdisciplinary Cancer treatment center: use of, knowledge about, and demand for CAM treatment options. Integr Cancer Ther. 2009;8(1):56-62.

\section{Publisher's Note}

Springer Nature remains neutral with regard to jurisdictional claims in published maps and institutional affiliations.
Ready to submit your research? Choose BMC and benefit from:

- fast, convenient online submission

- thorough peer review by experienced researchers in your field

- rapid publication on acceptance

- support for research data, including large and complex data types

- gold Open Access which fosters wider collaboration and increased citations

- maximum visibility for your research: over $100 \mathrm{M}$ website views per year

At BMC, research is always in progress.

Learn more biomedcentral.com/submissions 